\title{
Instillation rate effects of Exosurf on cerebral and cardiovascular haemodynamics in preterm
} neonates

\author{
Elie Saliba, Mahmoud Nashashibi, Marie-Catherine Vaillant, Charles Nasr, Jean Laugier
}

\begin{abstract}
The acute effects of surfactant instillation rate on the cerebral and cardiovascular haemodynamics were studied in a randomised trial of 27 preterm neonates with respiratory distress syndrome (RDS). Cerebral blood flow velocity (CBFV), mean arterial blood pressure (MABP), blood gases and electroencephalogram (EEG) were continuously recorded before, during, and for at least $\mathbf{1 0}$ minutes after the administration of surfactant. The measurements were repeated one, three, and six hours later. Left ventricular output (LVO) and ductal patency were assessed 10 minutes before and then one, three, and six hours after surfactant administration. Surfactant (Exosurf) was instilled rapidly over five minutes in 13 infants and slowly over 15 minutes in 14 infants. The rapid group showed a significant but transient increase (mean 38\%) in CBFV, a rise strongly related to an increase in carbon dioxide tension. No significant change in CBFV was observed in the slow group. There were no significant changes in EEG, MABP, LVO, or ductal shunting in either group.
\end{abstract}

The findings suggest that rapid instillation of Exosurf leads to an increase in CBFV and partial carbon dioxide pressure $\left(\mathrm{PCO}_{2}\right)$ and requires a close monitoring of blood gases to maintain adequate ventilation. Furthermore, the findings should alert clinicians to the need for slow infusion of Exosurf.

(Arch Dis Child 1994; 71: F174-F178)

There is abundant evidence that surfactant replacement therapy improves pulmonary function in preterm infants with respiratory distress syndrome (RDS). The effects of this treatment on intracerebral complications, such as periventricular cerebral haemorrhage or leucomalacia, are less certain. ${ }^{12}$ The administration of surfactant into the trachea has been associated with acute changes in cerebral blood flow velocity (CBFV) and electroencephalogram (EEG) abnormalities. ${ }^{3}$ Such changes, together with possible shunting through the ductus arteriosus, might increase the risk of cerebral lesions. We have already reported that 20 minutes after its administration Exosurf was not associated with any changes in CBFV and systemic haemodynamics. ${ }^{4}$ In that study the synthetic surfactant was instilled using a perfusion pump over 30 minutes. In view of this we attempted to determine in a randomised study whether the instillation rate of (Exosurf) will induce acute changes in CBFV, EEG, and cardiovascular haemodynamics including mean arterial blood pressure (MABP), left ventricular output (LVO), and patency of the ductus arteriosus.

\section{Methods}

The study was conducted on 27 consecutive newborn infants who had been admitted to the neonatal intensive care unit of the University Hospital, Tours, France. All babies entering the study had severe RDS, as judged by an a/A partial oxygen pressure $\left(\mathrm{PO}_{2}\right)$ ratio of less than $0 \cdot 22$. The criteria for diagnosing RDS were as follows: tachypnoea (more than 60 breaths/minute), substernal and intercostal recession; grunting and clinical diagnosis supported by radiological appearances. In all babies the lecithin:sphingomyelin (L:S) ratio in the tracheal aspirate was less than 1.5 , mean (SD) $1.15(0.31)$. The infants were randomly assigned to receive as quickly as possible after birth a synthetic surfactant (Exosurf) either rapidly over a period of five minutes or slowly over a period of 15 minutes. All infants were receiving mechanical ventilation with a fractional inspired oxygen $\left(\mathrm{FIO}_{2}\right)$ of $60 \%$ or more to maintain a transcutaneous carbon dioxide tension $\left(\mathrm{TcPCO}_{2}\right)$ between 5.3 and $6.6 \mathrm{kPa}(40$ and $50 \mathrm{~mm} \mathrm{Hg}$ ) and a transcutaneous oxygen tension $\left(\mathrm{TcPO}_{2}\right)$ between 8 and $9.3 \mathrm{kPa}$ (60 and $70 \mathrm{~mm} \mathrm{Hg}$ ).

Surfactant studies were begun when the infants were less than 12 hours old. After endotracheal suctioning surfactant was administered via the sideport on the special endotracheal tube adaptor without interrupting mechanical ventilation. During surfactant instillation, $\mathrm{FIO}_{2}$ was increased so that the arterial oxygen saturation $\left(\mathrm{SaO}_{2}\right)$ (Datex; pulse oximeter) remained within clinically accepted limits (95-97\%). The newborns were not hyperventilated. In the rapid instillation group a $5 \mathrm{ml} / \mathrm{kg}$ dose of surfactant was administered by bolus injection over five minutes. Surfactant was instilled in small bursts timed with inspiration, the infant's head being in the midline. In the slow instillation group the surfactant was given manually over 15 minutes, with the babies lying supine and the head in middle position. All infants received an additional dose 12 hours later. Only the effects of the first dose were studied. None of the infants was sedated nor were they paralysed. Consent for the investigation was obtained from the infants' parents before each study. 


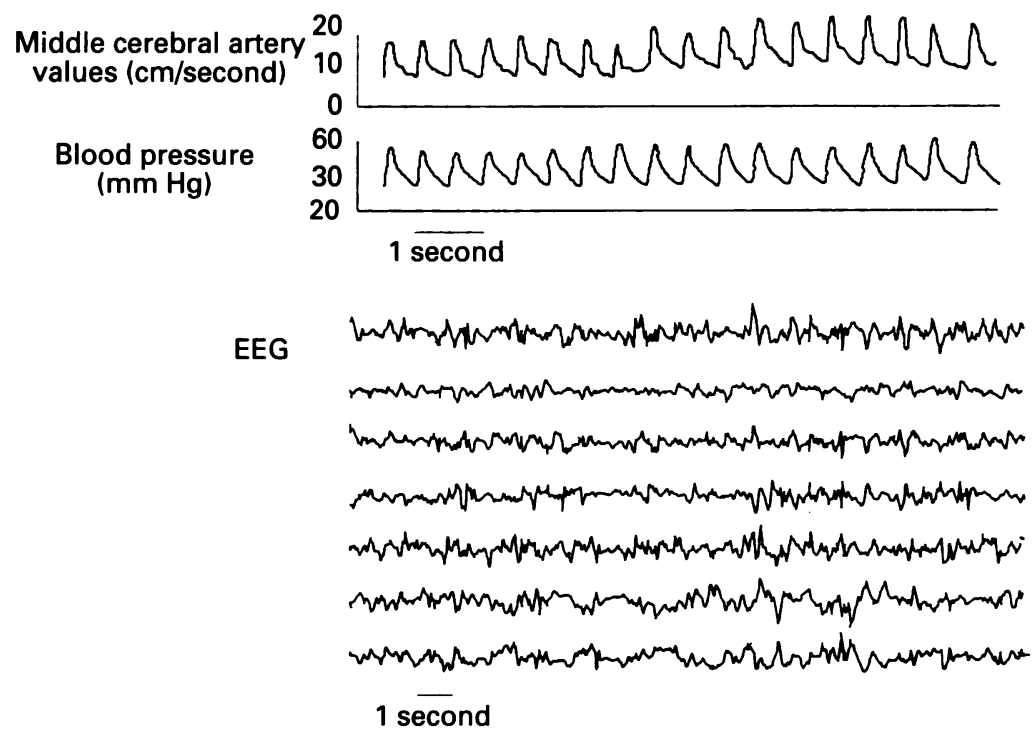

Figure 1 Simultaneous recording of middle cerebral artery CBFV (arterial blood pressure), and EEG during surfactant administration (raw data).

CBFV and EEG were measured continuously and data obtained every minute for a total of 30 minutes starting five minutes before surfactant administration. Measurements were repeated for 10 minutes at one, three, and six hours after surfactant administration. We have already described the methods used to measure CBFV over a long period of time. ${ }^{5}$ Briefly, a $4 \mathrm{mHz}$ pulsed wave miniature button transducer $(8 \mathrm{~mm} \times 2 \mathrm{~mm}$ ) (Vermon; Tours, France) was fixed to the skin by a soft adhesive tape placed over the baby's temporal bone at the point where the Doppler signal from the ipsilateral middle cerebral artery was maximum. This was achieved at a mean depth of $25 \mathrm{~mm}$ (range 23-28 mm). The Doppler unit was linked to a computer which ran a multiple signal analysis program (Department of Biophysics, INSERM Unit, Tours). This system calculated and stored on-line the time averaged mean flow velocity, together with $\mathrm{MABP}, \mathrm{TcPCO}, \mathrm{TcPO}_{2} \mathrm{SaO}_{2}$, and two channels (C3-01, C4-02) of EEG tracing recording. Measurements were made continuously and the results were averaged every minute. The data were recorded on computer hard disk for later analysis. For the EEG signal, the duration of low voltage tracing (below 10 $\mathrm{uV}$ ) was calculated by the program for every minute period. That way the recordings could be compared both among and within individuals. Simultaneously, raw EEG (seven channels) were recorded with standard calibration ( $50 \mathrm{uV}$, one second) and with a paper speed of $1.5 \mathrm{~cm} / \mathrm{second}$. Raw data for CBFV, arterial blood pressure, and EEG were also stored on computer hard disk (fig 1). MABP

Perinatal data (mean (SD) or range) in rapid and slow instillation groups

\begin{tabular}{|c|c|c|}
\hline & $\begin{array}{l}\text { Rapid instillation } \\
(n=13)\end{array}$ & $\begin{array}{l}\text { Slow instillation } \\
(n=14)\end{array}$ \\
\hline $\begin{array}{l}\text { Gestational age (weeks) } \\
\text { Birth weight (g) } \\
\text { Gender }(\mathrm{M} / \mathrm{F}) \\
\text { Mean airway pressure }\left(\mathrm{cm} \mathrm{H}_{2} \mathrm{O}\right) \\
\text { a/A } \mathrm{Po}_{2} \text { ratio }\end{array}$ & $\begin{array}{l}29 \cdot 0(1 \cdot 2) \\
1355(75) \\
7 / 6 \\
9 \cdot 45(2 \cdot 10) \\
0 \cdot 128(0 \cdot 048-0 \cdot 217)\end{array}$ & $\begin{array}{l}29 \cdot 9(1 \cdot 5) \\
1415(214) \\
7 / 7 \\
9 \cdot 70(2 \cdot 32) \\
0 \cdot 136(0 \cdot 042-0 \cdot 215)\end{array}$ \\
\hline
\end{tabular}

The $p$ values were not significant. was measured continuously via an umbilical artery catheter using a Baxter pressure transducer and was recorded on a Roche-Kontron monitor. The $\mathrm{PO}_{2}$ and $\mathrm{PCO}_{2}$ were measured transcutaneously (Supermon Kontron). Calibration was performed in vivo using arterial blood gas checks as reference values.

Doppler echocardiographic assessment of left ventricular output and ductus arteriosus were performed 10 minutes before treatment, and one, three, and six hours after the administration of surfactant. All subjects were studied with an ATL ultramark 4 scanner with range gated pulsed Doppler. Left ventricular output was calculated from the following formula:

\section{$\mathrm{LVO}=$ mean velocity.vessel area.heart rate. ${ }^{6}$}

A $5 \mathrm{mHz}$ transducer was used for Doppler measurement. The Doppler sample volume was positioned at the sinotubular junction of the aorta by using a subcostal view. Angle correction was applied for the angle $\theta$. Systolic mean velocity was measured by tracing the middle of the most dense portion of the Doppler spectra. For at least three beats the velocity area was computed. Heart rate was measured from the $R-R$ interval. The aortic vessel diameter was determined by using a $7.5 \mathrm{mHz}$ transducer. A parasternal long axis view was used and the internal diameter was measured at the sinotubular junction in systole using two-dimensional echocardiographic images. The average of three measurements was used to calculate the vessel area according to the formula:

vessel area $=\pi$. (diameter) $2 / 4$.

The ductus was imaged from the high left parasternal position. The Doppler sample volume was placed in the pulmonary end of the duct and the flow pattern was recorded. The ductus was classified as patent when patency could be imaged and Doppler flow could be detected. Otherwise it was classified closed.

\section{STATISTICAL ANALYSIS}

Student's $t$ test and $\chi^{2}$ analysis were used to evaluate differences between variables of the two groups treated with different instillation rate of surfactant. For all repeated measurements, a two factor analysis of variance was carried out, the factors being time and instillation rate. Measurements were repeated on the first factor (time). The association of MABP, $\mathrm{TcPCO}_{2}$, and CBFV were assessed by multiple linear regression analysis. Changes in $\mathrm{TcPO}_{2}$ were not considered an independent effect of surfactant because $\mathrm{FiO}_{2}$ was adjusted as part of the administration protocol. A $p$ value of $<0.05$ was considered significant.

\section{Results}

A total of 27 patients were consecutively enrolled: 13 received a rapid instillation of surfactant and 14 received a slow instillation of 


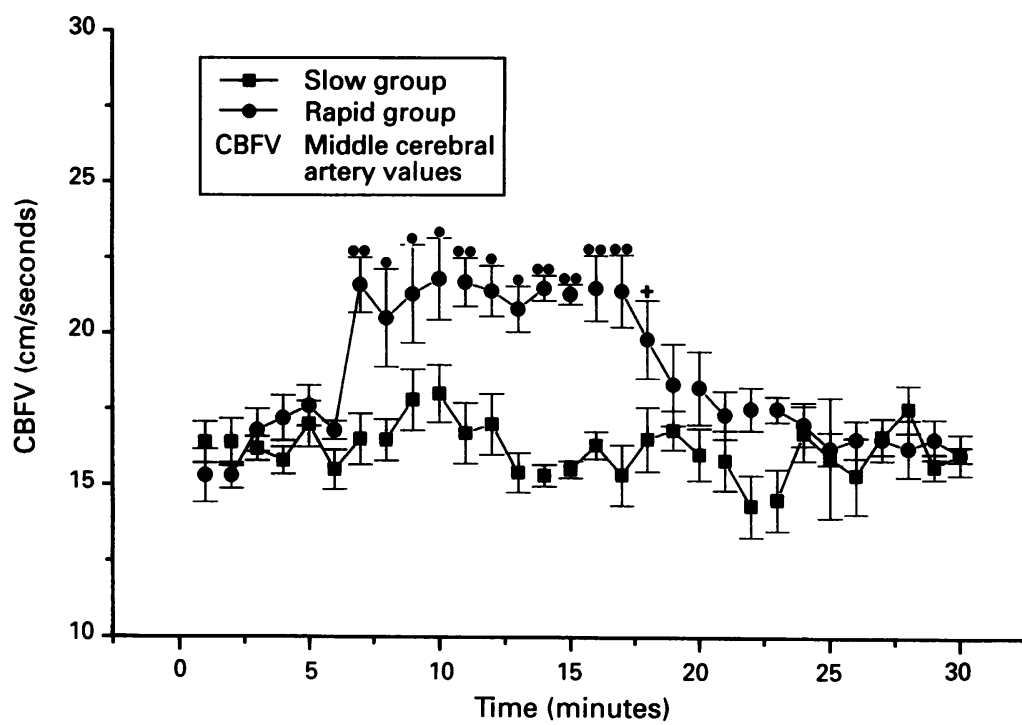

Figure 2 Middle cerebral artery $C B F V$ values obtained from rapid $(n=13)$ and slow $(n=14)$ group during surfactant administration. The arrow indicates the timing of endotracheal administration of surfactant. Comparisons are made between the two groups: $\dagger p<0.05,{ }^{\star} p<0.01,{ }^{\star \star} p<0.001$. Error bars represent $1 S D$ for the sample.

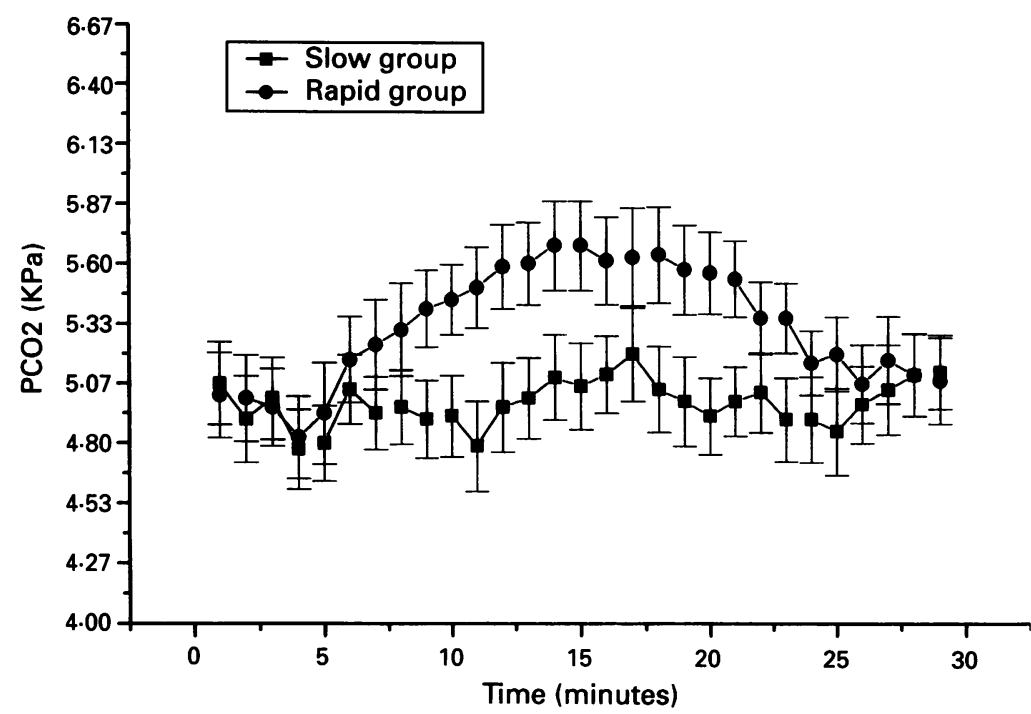

Figure 3 Transcutaneous $\mathrm{PCO}_{2}\left(\mathrm{TcPCO}_{2}\right)$ values obtained from rapid $(n=13)$ and slow $(n=14)$ group during surfactant administration. Error bars represent $1 S D$ for the sample.

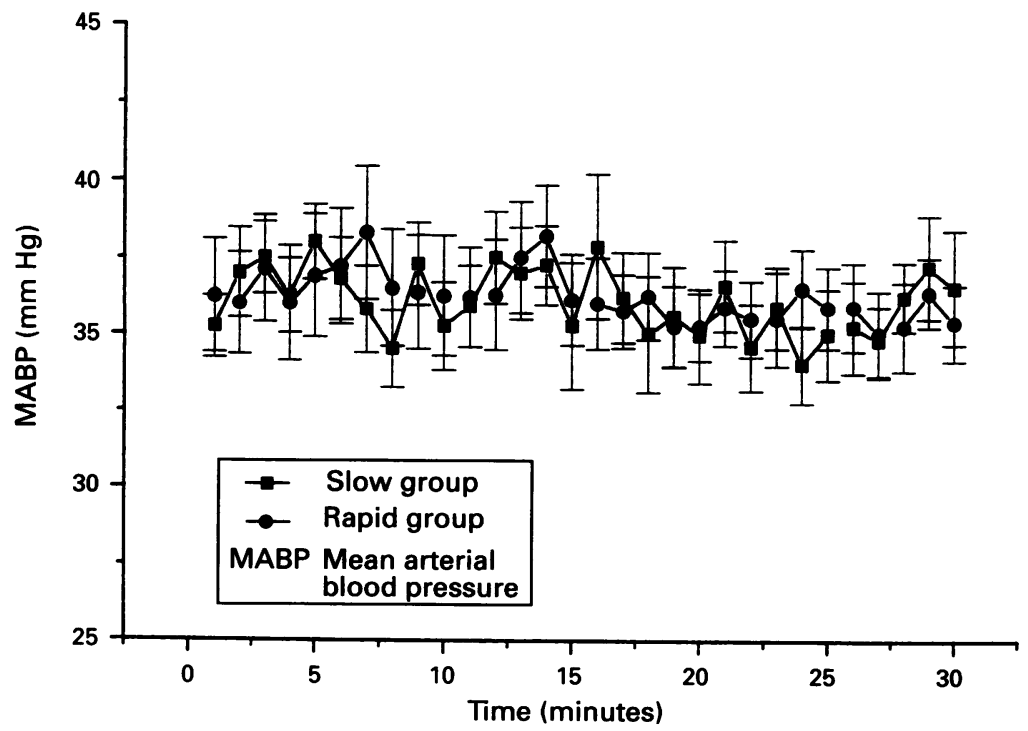

Figure $4 M A B P$ from five minutes before until 20 minutes after rapid surfactant administration ( $n=13)$ and until 10 minutes after slow surfactant administration $(n=14)$. Error bars represent $1 S D$ for the sample. surfactant. The two groups were similar with respect to gestational age and birth weight. Five minutes before surfactant instillation, a/A $\mathrm{PO}_{2}$ ratio, mean airway pressure, and MABP were not significantly different between the two groups (table).

The age at surfactant instillation was not significantly different for the rapid group from the slow rate group $(5 \cdot 28 \mathrm{H}, 3-9$ v $6.45 \mathrm{H}$, $3-10 ; \mathrm{p}=0.32$ ).

In the rapid instillation group there was a substantial but transient increase in CBFV and $\mathrm{TcPCO}_{2}$ in all infants (figs 2 and 3). Mean flow velocity in the middle cerebral artery increased by $38 \%$. The mean CBFV values before surfactant were $16.52(1.24) \mathrm{cm} / \mathrm{second}$ and the maximal CBFV after surfactant was $23(3 \cdot 2)$ $\mathrm{cm} /$ second $(\mathrm{p}<0.01)$. Peak systolic velocity and end diastolic velocity increased concomitantly. $\mathrm{TcPCO}_{2}$ accompanied the increase in $\mathrm{CBFV}$. The mean $\mathrm{TcPCO}_{2}$ values before surfactant were $4.93(0.23) \mathrm{KPa}$ and the maximal $\mathrm{TcPCO}_{2}$ after surfactant was $5.74(0.26) \mathrm{KPa}$ $(\mathrm{p}<0.01)$. Increases in $\mathrm{CBFV}$ and $\mathrm{TcPCO}_{2}$ rapidly reversed so that no net change was seen in the group as a whole 20 minutes after surfactant administration. However, individual results were different from the group as a whole. For infants showing a large change in $\mathrm{PCO}_{2}$, normalisation occurred after a longer interval. The changes in blood pressure were not significant within the group (fig 4). Multiple linear regression analysis showed that the largest part of the variation in CBFV was explained by a strong positive correlation with $\mathrm{TcPCO}_{2}(\mathrm{p}<0 \cdot 01)$. No correlation with MABP was found. $\mathrm{FIO}_{2}$ was increased from a mean (SD) of 68 (7)\% before surfactant to a mean (SD) of $75(9 \cdot 5) \%$ during surfactant $(p<0.05)$. In all infants $\mathrm{FIO}_{2}$ was back to its pre-surfactant value by the end of the 30 minute study period.

No significant changes in $\mathrm{CBFV}, \mathrm{TcPCO}$, and MABP were noted during the slow infusion of surfactant. $\mathrm{FIO}_{2}$ values were also not significantly different from the pre-surfactant values $(p=0 \cdot 16)$, but there was still considerable scatter in individual cases, mean change from the pre-surfactant values being $+8 \cdot 7 \%$ with a range of $-15 \%$ to $+23 \%$.

Compared with pre-surfactant values no significant changes in $\mathrm{CBFV}, \mathrm{PCO}_{2}$, and MABP were noted at one, three, and six hours after surfactant administration in both groups.

Ten minutes before surfactant instillation, mean LVO was $325 \mathrm{ml} / \mathrm{kg} /$ minute in the rapid group and $338 \mathrm{ml} / \mathrm{kg} / \mathrm{minute}$ in the slow group (NS). The mean and confidence intervals about the mean at one, three, and six hours are presented in fig 5. Within and between the two groups the surfactant had no effect on left ventricular output at one, three, and six hours after surfactant. For both groups, no significant changes occurred in the patency of the duct.

There was no significant depression of EEG during surfactant instillation and at one, three, and six hours afterwards.

The grade of improvement within six hours after surfactant treatment, as judged by the a/A $\mathrm{PO}_{2}$ ratio, was not statistically different 


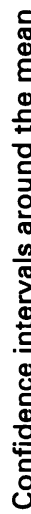

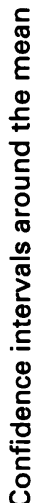

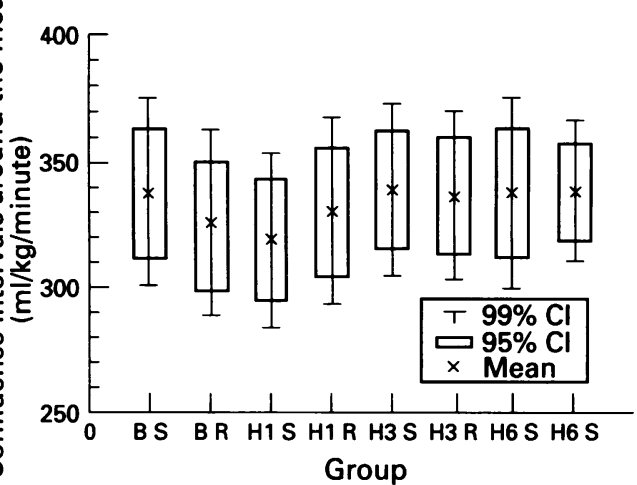

Figure 5 Values of left ventricular output obtained 10 minutes before surfactant administration in the slow group (BS) and the rapid group (BR), and at one hour (H1S, $H 1 R$ ), three hours (H3S; H3R), and six hours (H6S; $H 6 R$ ) after surfactant administration.

between the two groups. All infants received a second dose 12 hours after the initial treatment.

Cerebral ultrasound scans were normal in the 27 infants before surfactant. During the seven days following the administration of surfactant, three of the 13 infants in the rapid group developed germinal layer haemorrhages and two developed periventricular leucomalacia. Four of the 14 infants in the slow instillation group developed germinal layer haemorrhages. No association was found between the increase in CBFV and subsequent cerebral lesions.

\section{Discussion}

Using continuous recording of cerebral haemodynamics before, during, and for 20 minutes after rapid surfactant instillation, we showed that when surfactant was administered over a period of five minutes, there was an immediate and transient increase in CBFV. Unlike the rapid instillation group, the slow instillation group showed no significant changes in CBFV during the study period. Studies of CBFV after surfactant administration using Doppler technique have yielded conflicting results with increased, ${ }^{7}$ unchanged, ${ }^{8}$ or decreased CBFV. ${ }^{9}$ There are several factors that could explain these differences including: intermittent measurements which could overlook transient changes in CBFV; the type of surfactant natural or synthetic; and the mode of surfactant administration, meaning disconnection from the ventilator and bolus instillation. In our study we compared the instillation rate effects of a synthetic, slow acting surfactant without interrupting ventilation and oxygenation. Recently, Edwards et al, using the near infrared spectroscopy method (NIRS), studied the effect of a natural surfactant (Curosurf) on cerebral haemodynamics. ${ }^{10}$ They found a transient increase in cerebral blood volume and with a highly significant relation with $\mathrm{PaCO}_{2}$. The infants were disconnected from the ventilator circuit during surfactant administration. In our study the acute changes observed in $\mathrm{CBFV}$ in the rapid instillation group were closely related to changes in $\mathrm{PaCO}_{2}$. However, the magnitude of changes in CBFV could not be explained solely by the increase in $\mathrm{PCO}_{2}$. It is clear from fig 3 that the slow rise in carbon dioxide over 10 minutes (even allowing for the response time of $\mathrm{TcPCO}_{2}$ monitors) is not the whole explanation for the very rapid change $(38 \%)$ in CBFV. We speculate that the airway obstruction caused by the large volume of surfactant could have decreased venous return to the heart and increased cerebral blood volume. CBFV may also be subject to variation in $\mathrm{Po}_{2}$. In the present study, however, $\mathrm{FIO}_{2}$ was immediately adjusted during and after administration in response to change value observed by the monitors.

MABP remained stable in the rapid as well as the slow instillation group. Using a natural porcine surfactant, several authors have noticed a significant decrease in MABP as soon as two minutes after surfactant administration. ${ }^{39}$ It is likely that a rapid decrease in pulmonary vascular resistance, as a result of lung expansion, could have promoted ductal shunting and therefore lowered blood pressure. ${ }^{1112} \mathrm{~A}$ decrease of peripheral vascular resistance, as described by Skov et al $^{3}$ and by Cowan et al, ${ }^{9}$ may lead to a transient drop in blood pressure. In our study we found that until at least six hours after its administration synthetic surfactant did not result in a demonstrable increase in ductal shunting as judged by the LVO.

A transient but clear depression in EEG activity after administration of natural porcine surfactant has recently been reported. ${ }^{13}$ There was no clear explanation for this depression, although transient cerebral ischemia or hypoxia might be responsible. A significant decrease in MABP occurring at the same time as the cerebroelectrical depression was noticed by these authors.

It has been reported that slow infusion of surfactant may not distribute evenly in the lung and thus is less efficient for the treatment of RDS (Segerer H, personal communication). In the present study the two procedures - rapid and slow instillation - seemed to be equally effective in improving the acute clinical outcome as judged by the a/A $\mathrm{Po}_{2}$ ratio in the two groups 72 hours after the first dose of surfactant. Furthermore, we found no difference between the two groups concerning oxygen dependence at 28 days of life. Recently Zola et al, comparing three procedures for administration of bovine surfactant, found no difference in $\mathrm{FIO}_{2}$ improvement, mean airway pressure, and a/A $\mathrm{Po}_{2}$ ratio at 72 hours of life. ${ }^{14}$ These observations might be explained by the rapid distribution of intratracheally administered surfactant to the lungs regardless of the method of administration. ${ }^{15}$

We have reason to believe that cerebral haemodynamics and EEG perturbations observed by many authors during surfactant administration are not related to any one factor but to several, including the initial severity of the respiratory disease, the mode of administration, and especially the type of surfactant used. The effect of the type of surfactant needs to be verified by a randomised controlled trial 
comparing the acute effects on cerebral and systemic haemodynamic of natural and synthetic surfactants. In the meantime we recommend slow instillation of synthetic surfactant over at least 15-20 minutes and close monitoring of haemodynamics and blood gases during surfactant treatment.

1 Mc Cord FB, Curstedt T, Halliday HL, McClure G McReid M, Robertson B. Surfactant treatment and incidence of intraventricular haemorrhage in severe respiratory distress syndrome. Arch Dis Child 1988; 63: $10-6$.

2 Horbar JD, Soll RF, Schachinger H, Kewitz G, Versmold HT, Lindner W, et al. A European multicentre randomised controlled trial of single dose surfactant therrandomised controlled trial of single dose surfactant therapy for idiopathic respira

3 Skov L, Bell A, Greisen G. Surfactant administration and the cerebral circulation. Biol Neonate 1992; 61 (suppl 1): 31-6.

4 Saliba E, Autret E, Nasr C, Suc AL, Laugier J. Perinata pharmacology and cerebral blood flow. Biol Neonate 1992 62: 252-7.

5 Saliba E, Chantepie A, Autret E, Gold F, Pourcelot L, Laugier J. Effects of indomethacin on cerebral hemodynamics at rest and during endotracheal suctioning in preterm

6 Goldberg SJ, Sahan DJ, Allen HD, Valdes-Cruz LM, Honecke H, Carnahan Y. Evaluation of pulmonary and systemic blood flow by 2-dimensional Doppler echocardiography using fast Fourier transform spectral echocardiography using fast Fourier tran
analysis. Am $\mathcal{F}$ Cardiol 1982; 50: 1394-400.
7 Van de Bor M, Ma EJ, Walther FJ. Cerebral blood flow velo city after surfactant instillation in preterm infants. F Pediatr 1991; 118: 285-7.

8 Jorch G, Rabe H, Garbe M, Michel E, Gotner L. Acute and protracted effects of intratracheal surfactant application on internal carotid blood flow velocity, blood pressure and carbondioxide tension in very low birth weight infants. Eur $\mathcal{F}$ Pediatr 1989; 148: 770-3.

9 Cowan F, Whitelaw A, Wertheim D, Silverman $M$ Cerebral blood flow velocity changes after rapid adminisCerebral blood flow velocity changes after rapid adminis-

10 Edwards AD, McCormick DC, Roth CE, Elwell CE Peebles DM, Cope M, et al. Cerebral hemodynamics effects of treatment with modified natural surfactan investigated by near infrared spectroscopy. Pediatr Re 1992; 32: 532-6.

11 Vidyasagar D, Maeta H, Raju TNK, John E, Bhat T, Go M et al. Bovine surfactant (Surfactant TA) therapy in immature baboons with hyaline membrane disease. Pediatrics 1985; 75: 1132-42.

12 Evans N, Moorcraft J. Effect of patency of the ductus arteriosus on blood pressure in very preterm infants. Arch arteriosus on blood pressure in

13 Hellström-Westas L, Bell AH, Skov L, Greisen G, Svenningsen NW. Cerebroelectrical depression following surfactant treatment in preterm neonates. Pediatrics 1992 89: 643-7.

14 Zola EM, Gunkel JH, Chan RK, Lim MO, Knox I, Feldman BH, et al. Comparison of three dosing procedures for administration of bovine surfactant to neonate with respiratory distress syndrome. 7 Pediatr 1993; 122: 455-9.

15 Davis JM, Russ GA, Metlay L Dickerson B, Greenspan BS. Short-term distribution kinetics of intratracheally admin Short-term distribution kinetics of intratracheally admin-
istered exogenous lung surfactant. Pediatr Res 1992; 31: istered 